\title{
Life cycle assessment and possible impacts of CFRPs for space applications
}

\author{
Ioannis Xiarchos, Athanasios K. Morozinis, Costas Charitidis*
}

Research Lab of Advanced, Composite, Nanomaterials and Nanotechnology (R-NanoLab), School of Chemical Engineering, National Technical University of Athens, 9 Heroon Polytechniou str., Zographos, 15780, Athens, Greece, charitidis@chemeng.ntua.gr*

\begin{abstract}
Life-cycle assessment, or LCA, is an environmental management technique that considers all the aspects of resources use and environmental releases associated with an industrial product, service or a system. LCA is intended for comparison and not absolute evaluation, in this way assisting decision makers when choosing between alternative courses of action. In Space applications, LCA is used to evaluate environmental impacts from early research \& design stage to the mission end according to United Nations General Assembly declaration for the need of development of Space Technologies that minimize the environmental impact. More specifically, in the frame of SpaceCarbon project, preliminary research design laboratory activities have been studied by the Life Cycle Assessment technique and environmental impact hotspots were identified, mainly the use of carbon fibres and epoxy resin which affect mainly "climate" and "resources" environmental damage categories. This is explained by the high energy intensity of carbon fibres production, petrochemical origin of carbon fibre preform, epoxy resin toxicity and related emissions $\left(\mathrm{NO}_{\mathrm{x}}, \mathrm{SO}_{2}\right)$. It is worth pointing out though, that weight reduction and related energy savings (e.g. reduction of fuels consumption), longevity of space technology application in the use phase are beneficial for the environmental impacts minimization.
\end{abstract}

\section{Introduction}

Life-cycle assessment (LCA) is an environmental accounting and management technique that considers all the facets of resource use and environmental releases associated with an industrial product, material service or a system from cradle to grave [1-2]. Specifically, it is a holistic and comprehensive method for assessing all direct and indirect environmental impacts across the full life cycle of a product, system that covers a range of activities, from raw materials acquisition, the production through the use, and final disposition of a product (disposal or reuse). LCA is a relative tool intended for comparison and not absolute evaluation, thereby helping decision makers compare all major environmental impacts when choosing

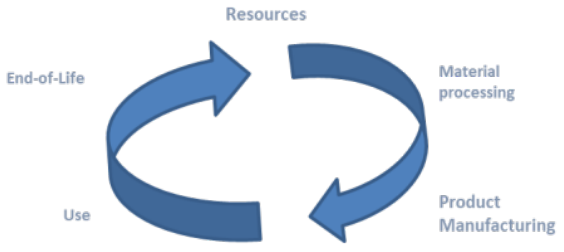

Figure 1. Constituents of Life Cycle Analysis between alternative courses of action. LCA is an environmental management tool that informs decision makers, but other decision criteria, such as cost and performance, should also be considered in order to make a well-balanced decision. The "cradle to grave" approach of LCA is depicted in Fig. 1. 
It is worth to be mentioned that Life Cycle Assessment (LCA) is a well-defined and standardized methodology, regulated by the ISO norms [3-4] and the International Life Cycle Data (ILCD) Handbook [5]. According to the aforementioned guidelines, Life cycle Assessment is carried out in four stages: I') Goal and Scope, ii) Life cycle inventory, iii) Life Cycle impact assessment and iv) interpretation of the results. The stages along with their interactions are depicted in Fig. 2.

LCA has great potential for leading into development of products and processes with improved environmental credentials when used at the early research stage, not only to compare novel processing with existing commercial alternatives but to help identify environmental hotspots. However, great potential or environmental improvement exists using LCA within the design stage of any product or process where it is estimated that about $80 \%$ of all environmental effects associated with a

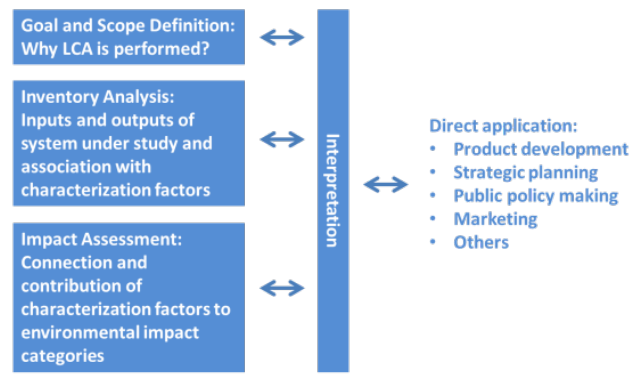

Figure 2. LCA stages as defined in ISO 14040 standard product are identified in the design phase of development [6]. Indeed, determining where improvements can be brought about while a process is still at laboratory stage or pilot scale can be key to unlocking the environmental improvement potential, forming the environmental eco-design [7].

In the field of Space Applications, European Space Agency (ESA) along with NASA are conforming to the United Nations General Assembly declaration of Committee on the Peaceful Uses of Outer Space: «...should promote the development of technologies that minimize the environmental impact of manufacturing and launching space assets" [8]. In the scientific bibliography, studies have been performed on the dispersion effects from the propellants used during the launch phase [9-12].Also, relevant studies include solid and liquid propellant issues, launch vehicles and impact to stratosphere, and space manufacturing [13]. Concerns have been raised regarding the volume of launches and the type of propellant used for launches, which might need to be regulated and controlled due to the potential ozone depletion [14]. NASA considers LCA to be a means to inform decision makers about inputs into the broader strategic planning process to better risk informed decisions and mission success [15].The ESA Clean Space Initiative (CSI) Eco Design branch started to use LCA in 2013 to study environmental impacts of a whole mission from early research stage to the mission end -of - life (e.g. intensive preliminary research, the use of advanced materials and processes, very low production runs and propellants) and a key - finding was that the launch - related activities had a dominant contribution to the environmental impacts [16].

\section{Methodology}

Life-cycle assessment (LCA) is a technique that has been used to assess environmental impacts associated with all stages of a product's life, from raw material extraction through materials processing, manufacture, distribution, use, repair and maintenance, and disposal or redevelopment of emerging technologies, also "cradle to grave" assessment.

In the case of the ongoing LCA, firstly a survey was developed as a tool to obtain the necessary information for the evaluation of the processes that will be developed in the framework of the SpaceCarbon project. The survey has four main categories: raw materials, energy, emissions and wastes, and for each one, detailed information was given 
about the source, the functional unit and the quantities. A process tree was utilized to structure the LCA of SpaceCarbon materials (Figure ). SimaPro software and IMPACT $2002+$ life cycle impact methodology have been chosen as the most appropriate due to compliance with ISO 14040:2006, ISO 14044:2006 and European regional validity [17].

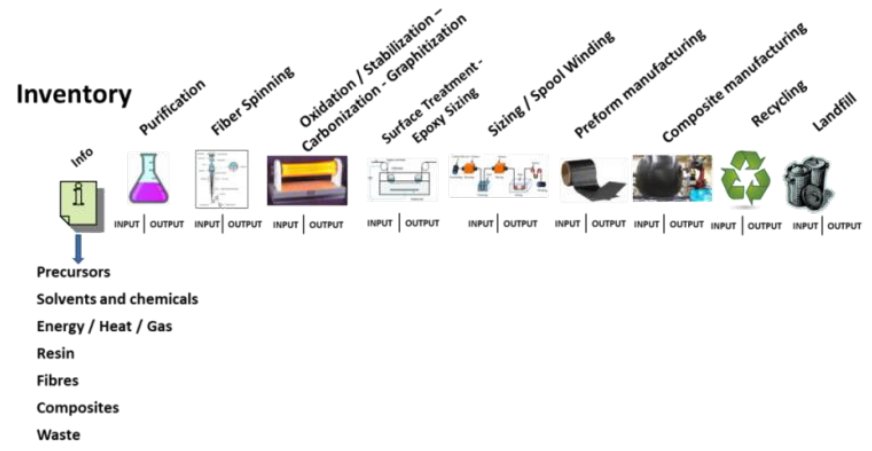

Figure 3. Process tree of SpaceCarbon materials

Great potential or environmental improvement exists using LCA within the design stage of any product or process: about $80 \%$ of environmental effects associated with a product are identified in the design phase of development [18]. Determining where improvements can be brought about while a process is still at laboratory stage or pilot scale can be key to unlocking the environmental improvement potential, forming the environmental ecodesign [19]. In this scope, mid- and end-points in LCA analysis are determined to quantitate the results of the input quantities (Fig. 4).

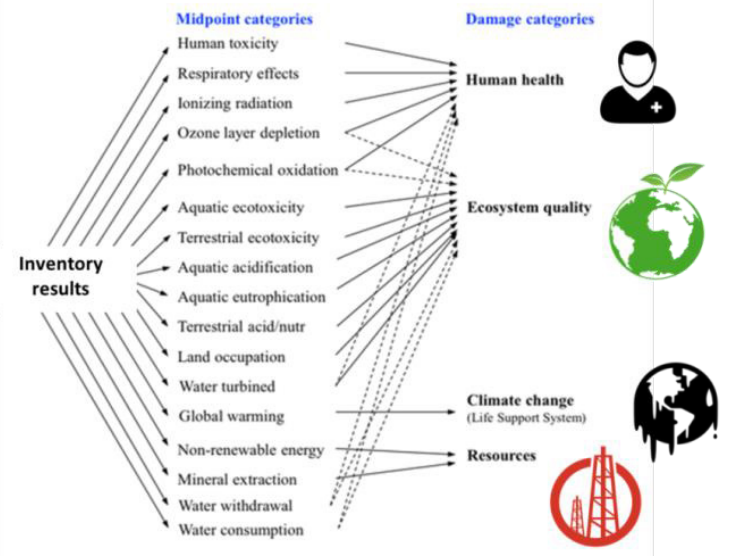

Figure 4. Mid-point and End-point (Damage) indicators of LCA analysis

\section{Results \& Discussion}

A comparison scenario was utilized to monitor the impact of using space grade CFRPs to GFRPs in LCA. By assuming: i) the same tensile modulus for the glass fiber - epoxy composite and CFRP, ii) same epoxy resin material, iii) the energy consumption of composite manufacturing and iv) the waste amount for composite parts is the same, the mass fraction of the required CFs to achieve the highest modulus of a GFRP composed by 70 wt \% by high-strength glass fibers was used. Ideal composites follow the "law of mixture" in case of Young Modulus [20]: 


$$
E_{\text {comp }}=\left(1-V_{f}\right) \cdot E_{\text {matrix }}+V_{f} \cdot E_{f}
$$
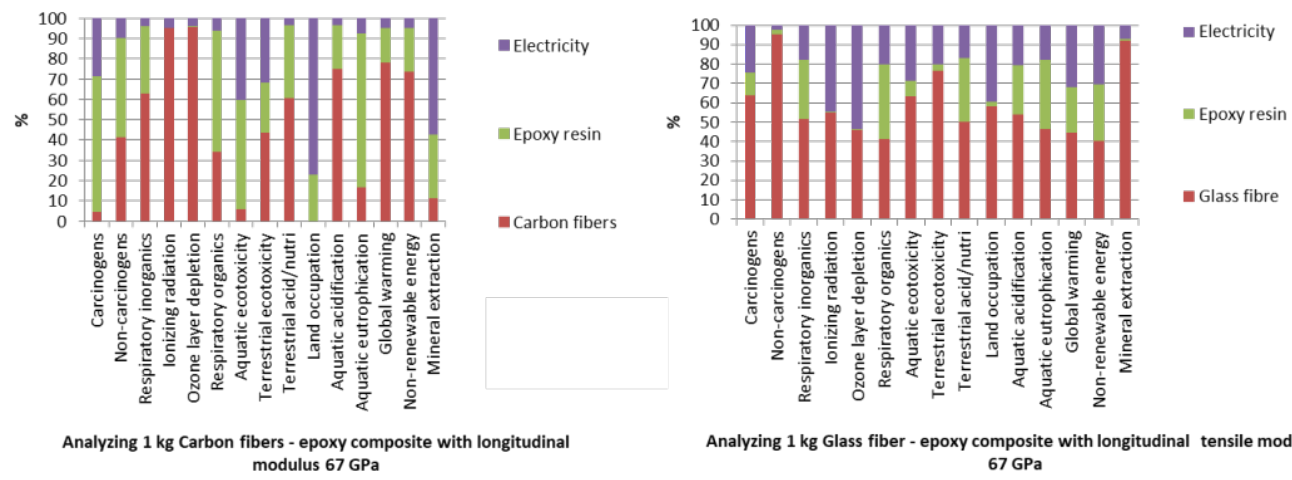

Analyzing $1 \mathrm{~kg}$ Glass fiber - epoxy composite with longitudinal tensile modulus $67 \mathrm{GPa}$

Figure 5. Analyzing $1 \mathrm{~kg}$ a) GFRP, b) CFRP with longitudinal modulus $67 \mathrm{GPa}$

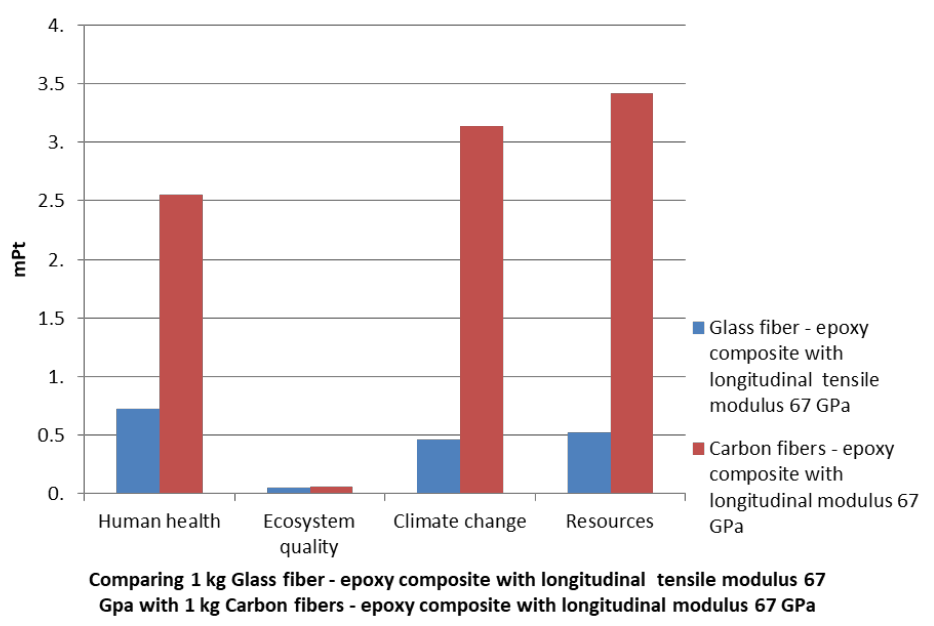

Figure 6. Composites effect score. The value of $1 \mathrm{Pt}$ (eco-point) is representative for one thousand of the yearly environmental load of one average European inhabitant. It is calculated by dividing the total environmental load in Europe by the number of inhabitants and multiplying it with 1000

The higher environmental impact of Carbon Fibers is attributed to the process requirements for energy, inert gas, and chemicals, while longevity of CFRP and savings with significant weight reduction compared to GFRPs is not considered. Thus, the high emissions of $\mathrm{NO}_{\mathrm{x}}, \mathrm{SO}_{2}$ caused by the carbon fiber production \& epoxy resin [21 -23] and high energy consumption of electricity generated from fossil fuels dominate the LCA of CFRPs [23].

By utilizing INEGI input on CFRP manufacturing process, the impact in all categories is summarized in Figure . 


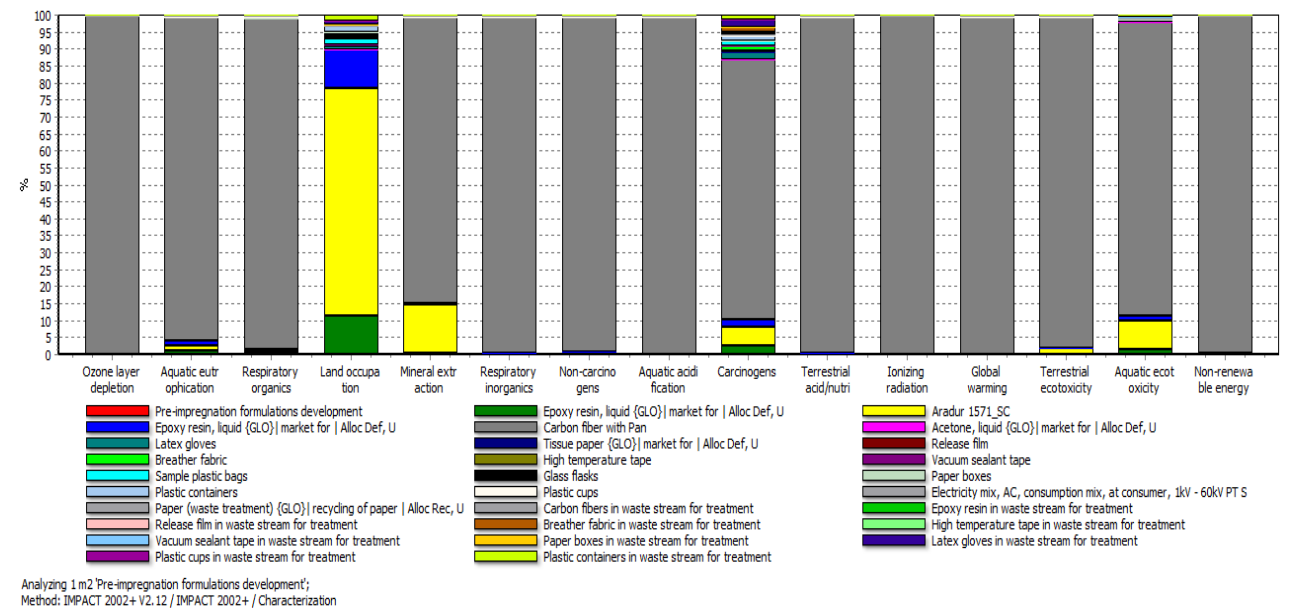

Figure 7. Impact of CFRP manufacturing resources to LCA: INEGI case

It can be seen that Carbon fibres are responsible for the main environmental impact the resources used during the synthesis of CFs [24], whereas a high impact is demonstrated by Aradur (epoxy resin used) in category "Land occupation", which is explained by the emissions of $\mathrm{NO}_{\mathrm{x}}, \mathrm{SO}_{2}$ associated to its production and its toxicity itself (dicyandiamide component) which is responsible for possible acidification, aquatic toxicity) affecting agricultural land usage [25].

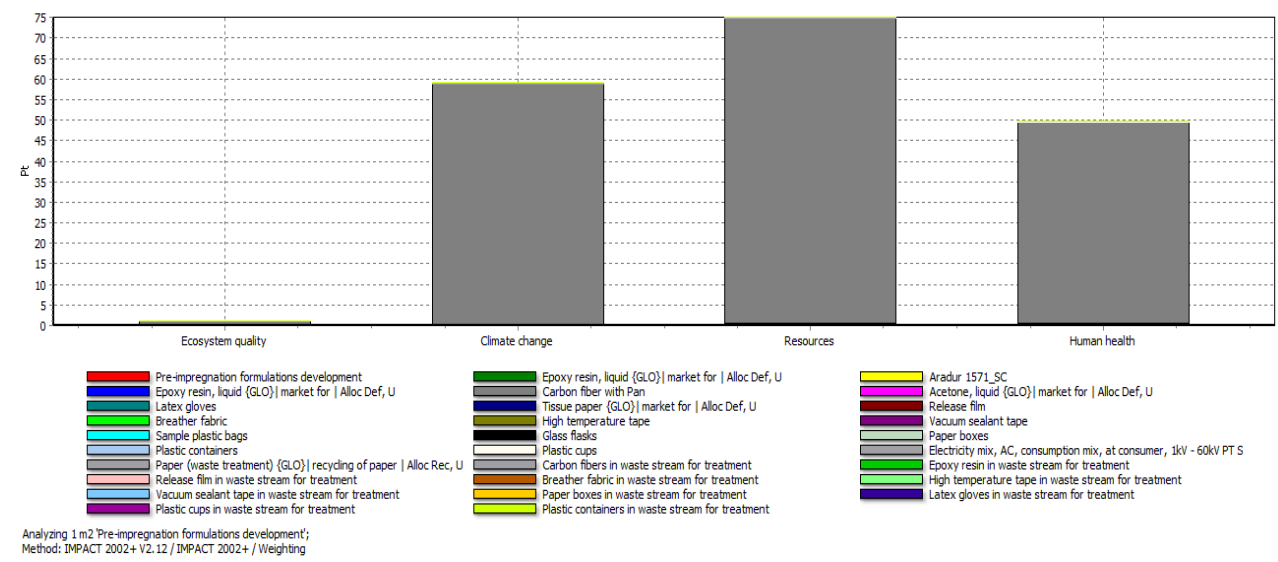

Figure 8. INEGI composites effect score. The value of $1 \mathrm{Pt}$ (eco-point) is representative for one thousand of the yearly environmental load of one average European inhabitant. It is calculated by dividing the total environmental load in Europe by the number of inhabitants and multiplying it with 1000

By utilizing AVIO input on CFRP manufacturing process, the impact in all categories is summarized in Figure .

It is indicated that the highest impact is generated from electricity that is consumed during carbon fiber production. Especially, fossil fuels are used for energy generation and affect the category "Land occupation" due to impacts on biodiversity and soil quality [26]. Also, epoxy resin impact is attributed to emissions of NOx, SO2 during production and its toxicity itself [25]. 


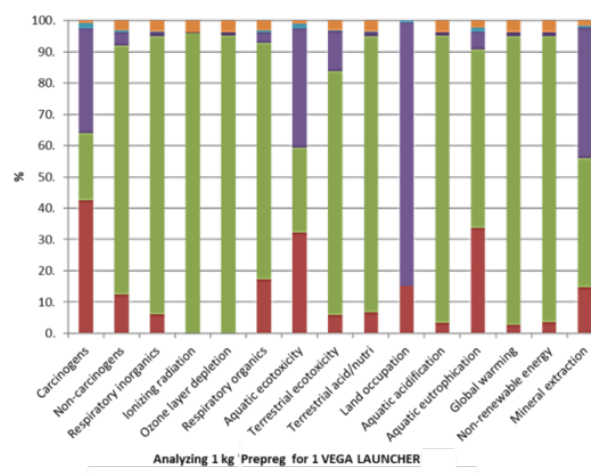

Figure 9. Impact of CFRP manufacturing resources to LCA: AVIO case.

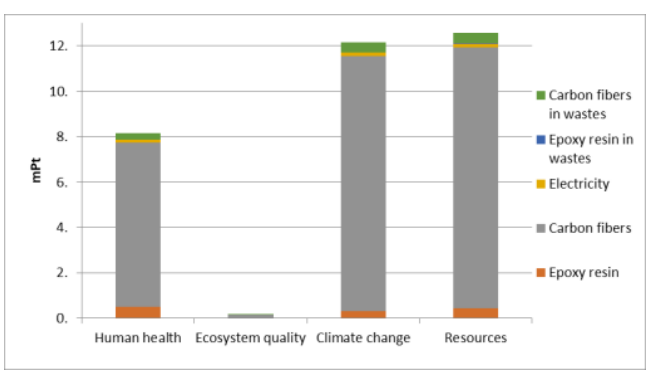

Figure 10. Analysing $1 \mathrm{~kg}$ Prepreg for 1 VEGA

Again, in this case, the dominant impact is a result of Carbon fibres production process.

By utilizing SGL input on CFs synthetic process, the impact in all categories is summarized in . 11 .

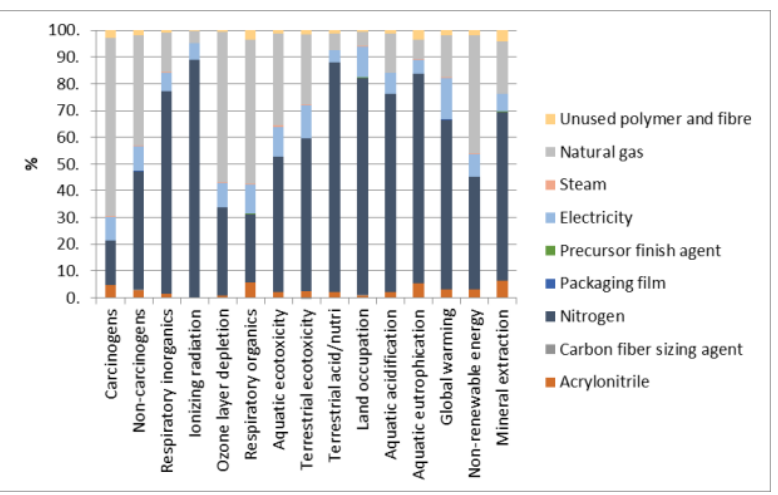

Figure 11. Analyzing $1 \mathrm{~kg}$ SGL Carbon Fibers; Method: IMPACT 2002+ V2.12 / IMPACT 2002+ / Characterization

Nitrogen gas consumption and the high energy intensity in production of CFs were identified as the origins for the determination of majority of metrics and are responsible for the release of $\mathrm{NO}_{\mathrm{x}}$ gases, nitrosamines, etc. Natural gas is second in ranking related to its environmental impact due to its use as a fossil fuel to generate energy, which increased $\mathrm{CO}_{2}$ emissions and entailed greenhouse effects. [27] In addition, acrylonitrile is produced from an intensive energy process with the use of toxic organic chemicals [28]. 


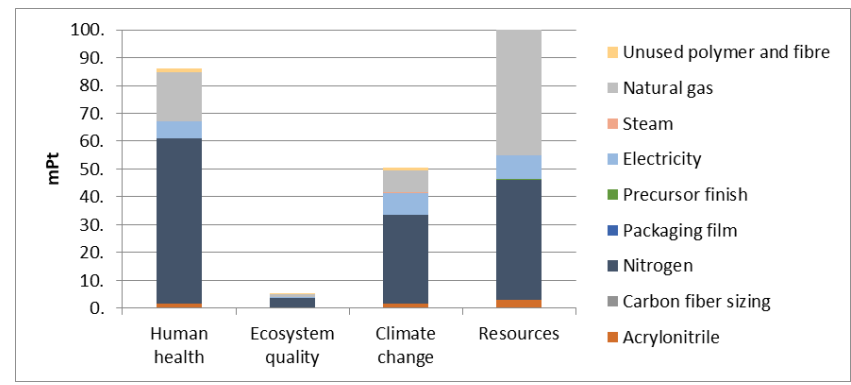

Figure 12. Analyzing $1 \mathrm{~kg}$ SGL Carbon Fibers; Method: IMPACT 2002+ V2.12 / IMPACT 2002+ / Weighting. The value of $1 \mathrm{Pt}$ (eco-point) is representative for one thousand of the yearly environmental load of one average European inhabitant. It is calculated by dividing the total environmental load in Europe by the number of inhabitants multiplying it with 1000

The profile of environmental impacts of the aforementioned processes can be improved mainly in the following way by implementing recycling of carbon fibers and epoxy resin wastes and process optimization.

\section{Conclusions}

The initial exercise already confirmed that the main environmental impacts for the development of pre-impregnation formulations are dominated by the carbon fibres (CF) use. This arises from the fact that CF production is an energy intensive process derived from PAN (polyacrylonitrile) precursor, which is a derivative from petrochemical industry.

On the other side, an also significant impact results from the epoxy resin application, with $\mathrm{NOx}$ and $\mathrm{SO} 2$ emissions during its production as well as its toxicity mainly for humans and aquatic environments.

And, in overall, the first results point to [29-30]:

- A comparison of the environmental performance of CF based composites products with that of traditional material solutions at a product level requires a thorough analysis of the complete life cycle of the product.

- The production of matrix and fiber materials generates considerable environmental impacts, especially because of the energy intensity of carbon fiber production.

- End-of-life processing creates comparatively less impact and therefore does not dominate environmental trade-off considerations.

- Depending on the application, the environmental payback during the product-use phase can be substantial: In aerospace applications, for example, weight reductions and related energy savings clearly dominate the life-cycle assessment.

- For applications with less energy-intensive use phases, such as automotive structures, the trade-off between environmental impacts caused during production and expected savings during use are less obvious and should be studied on a caseby-case basis.

- The environmental impact during the life-cycle of a composite is determined by the longevity of the composite.

- Great potential or environmental improvement exists using LCA within the design stage of any product or process where it is estimated that about $80 \%$ of all environmental effects associated with a product are identified in the design phase of development. 
- Determining where improvements can be brought about while a process is still at laboratory stage or pilot scale can be key to unlocking the environmental improvement potential, forming the environmental eco-design.

This study took place in the framework of H2020 Project "SpaceCarbon - European Carbon Fibres and Pre-Impregnated Materials for Space Applications" (GA No. 776391).

\section{References}

[1] M.A Curran, Encyclopedia of Ecology, 4, 2nd Edition, 359 -366 (2016)

[2] M. L. Brusseau, Sustainable Development and Other Solutions to Pollution and Global Change. In Environmntal and Pollution Science, 585-603 ( Academic Press, ,2019)

[3] International Standardization Organization. Environmental Management-Life Cycle Assessment - Principles and Framework (ISO 14040:2006)

[4] International Standardization Organization. Environmental management. Life cycle assessment. Requirements and guidelines (BS EN ISO 14044:2006+A1:2018)

[5] International Reference Life Cycle Data System (ILCD) Handbook - General guide for Life Cycle Assessment - Detailed guidance. 1st edition, Publications Office of the European Union (2010)

[6] M. Khasreen, P. F. Banfill, , G. Menzies, Sustain., 1, 674-701(2009).

[7] A. C. Hetherington,A. L. Borrion, , O. G. Griffiths,, M. C.McManus, Int. Jour. of L. C. Ass., 19, 130-143 (2013)

[8] Report of the Committee on the Peaceful Uses of Outer Space, 60th session, iv, 47 (2017)

[9] R. R. Bennett, J.C. Hinshaw, M. W. Barnes, Act. Astron. 26, 531-541(1992)

[10] R. Bennett,, A.McDonald, AIAA Paper, 98-3850 (1998)

[11] B. Brady, 1. Martin, V. Lang, Brady, J. of Sp. and Rock., 36(4), 774 - 779 (1997)

[12] N. Murray, S. Bekki, R. Toumi, T. Soares, EUCASS Proceedings Series 4, 671-688 (2013)

[13] S. Durrieu, R.F.Nelson, Spac. Pol., 29, 238-250 (2013)

[14] M. Ross, D. Toohey, M. Peinemann, P.Ross, Astropol., 7, 50-82 (2009)

[15] T. Chytka, R. Brown,, A. Shih, J.D. Reeves, J.Dempsey, AIAA Paper 2006-7027 (2006).

[16] S.S. Neumann, Environmental Life Cycle Assessment of Commercial Space Transportation Activities in the United States, Doctoral Thesis, Department of Civil Engineering, The University of Texas at Arlington (2018)

[17] O. Jolliet, M. Margni, R. Charles, S. Humbert, J. Payet G. Rebitzer, R. Rosenbaum,, Int. J. of L. C. Ass., 8, 324-330 (2003)

[18] U. Tischner, How to Do EcoDesign: A Guide for Environmentally and Economically Sound Design: (Art Books International Limited, 2000)

[19] A.C. Hetherington, A.L. Borrion, O.G. Griffiths, M.C. McManus, Int. J. of L. C. Ass., 19, 130$143(2014)$

[20] A.Kato, A. Tohsan, S. Kohjiya, T.Phakkeeree, P. Phinyocheep, Y.Ikeda, Progress in Rubber. Nanocomposites( Woodhead Publishing, 2017)

[21] M.R. Kabir, B. Rooke, G.D.M. Dassanayake, B.A.Fleck, Renew. En., 37, 133-141. (2012)

[22] B.Xue, Z. Ma,Y. Geng,,P. Heck,,W. Ren, M.Tobias et al., Renew. and Sust. En. Rev., 41, 338$346(2015)$

[23] S.Das, Int. J. of L. C. Ass., 16, 268-282 (2011)

[24] J.R. Duflou, Y. Deng, K. Van Acker, W. Dewulf, MRS Bull., 37, 374-382 (2012)

[25] J. Parameswaranpillai, D. Vijayan, Micro and Nanostructured Epoxy/Rubber Blends (WileyVCH Verlag GmbH \& Co. KGaA, 2014)

[26] N. Butt, H.L. Beyer, J.R. Bennett, D. Biggs, R Maggini, M. Mills, et al. Science, 342, 425-426 (2013)

[27] F.Barbir, T. Veziroglu, H.Plassjr, Int. J. of Hydr. En., 15, 739-749 (1990)

[28] D. Cespi, F. Passarini, E. Neri, I. Vassura, L. Ciacci, F.Cavani, J. of Clean. Prod. 69, 17-25 (2014)

[29] C. Soutis, Sc. Mat. A. Eng., 412, 171-176 (2005)

[30] Y.S. Song, J.R. Youn, T.G. Gutowski, Comp. A: Appl. Sc. and Man., 40, 1257-1265 (2009) 